\title{
Implementation of a health education program in Asia, comparing Thailand, Indonesia, and Japan
}

Koji Terasawa ${ }^{\mathrm{a}, *}$, Adiatmika I Putu Gede ${ }^{\mathrm{b}}$, Adiputra I Nyoman ${ }^{\mathrm{b}}$, Suchinda Jarupat Maruo ${ }^{\mathrm{c}}$, Surintorn Kalampakorn ${ }^{\mathrm{d}}$, Toshiaki Watanabe ${ }^{\mathrm{a}}$, Fumihito Sasamori ${ }^{\mathrm{e}}$, Kazuki Kobayashi ${ }^{\mathrm{e}}$, Hisaki Akasakie, Masao Okuhara ${ }^{\mathrm{f}}$, Ryoji Uchiyama ${ }^{\mathrm{g}}$, Kazuki Ashida ${ }^{\mathrm{g}}$, Hisaaki Tabuchi ${ }^{\mathrm{h}}$, Mizue Kayama ${ }^{\mathrm{e}}$, Takao Futagami ${ }^{\mathrm{i}}$ and Takashi Nagai ${ }^{\mathrm{j}}$

${ }^{a}$ Faculty of Education, Shinshu University, Nagano, Japan

${ }^{\mathrm{b}}$ Department of Physiology, Faculty of Medicine, Udayana University, Denpasar Bali, Indonesia

${ }^{\mathrm{c}}$ Department of Occupational Health and Safety, Faculty of Public Health, Mahidol University, Bangkok, Thailand

${ }^{\mathrm{d}}$ Department of Public Health Nursing, Faculty of Public Health, Mahidol University, Bangkok, Thailand ${ }^{\mathrm{e}}$ Faculty of Engineering, Shinshu University, Wakasato Nagano, Japan

${ }^{\mathrm{f}}$ Department of Applied Information Engineering, Faculty of Engineering, Suwa University of Science, Toyohira Chino, Nagano, Japan

${ }^{g}$ National Institute of Technology, Nagano College, Nagano, Japan

${ }^{\mathrm{h}}$ Department of Psychology, University of Innsbruck, Innsbruck, Austria

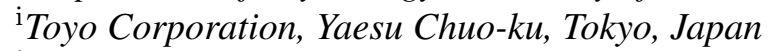

${ }^{\mathrm{j}}$ Institute of Technologists, Gyoda, Saitama, Japan

Received 15 September 2020

Accepted 19 December 2021

\begin{abstract}
.
BACKGROUND: The global community is faced with aging societies, which will result in increased health care costs. we have been introducing our International Organization for Standardization (ISO)-certified health education system in Thailand and Indonesia.

OBJECTIVE: The purpose of this study was to collect data on the effects of this ISO-certified health education system, to extend the healthy life expectancy and to study the feasibility of implementing this program and in new social contexts. METHODS: We implemented the health education program recruiting 43, 114 and 119 participants, respectively, in Japan, Thailand and Indonesia. The participants' conditions before and after the program were determined through anthropometry, physical fitness tests, blood chemistry tests, brain function tests and pedometry.

RESULTS: Regarding pedometry, the Japanese participants took the highest number of daily steps on average, followed by the Indonesian and Thai participants. In the 10-m obstacle walk, the Thai and Indonesian participants had significantly increased times. Furthermore, the differentiation reaction time, reverse differentiation reaction time, total number of "misses", total number of "mistakes" and total number of errors significantly improved.
\end{abstract}

\footnotetext{
${ }^{*}$ Corresponding author: Koji Terasawa, Faculty of Education, Shinshu University, 6-Ro Nishinagano, Nagano, 380-8544, Japan. E-mail: kterasa@shinshu-u.ac.jp.
} 
CONCLUSION: It is possible to implement a program of an ISO-certified health education system, but how to develop exercise habits is important.

Keywords: Brain function, health promotion, pedometer, physical fitness

\section{Background}

In 1978, the World Health Organization defined and advocated for "primary health care," which concerns health care provided in communities with a focus on prevention and treatment [1]. In 1986, this concept was redefined as "health promotion," which involves enabling people to increase their control over their health [2]. Sustained physical activity reduces the risk of lifestyle-related diseases [3]; however, there are situations in which it is difficult to maintain physical activity [4].

Since 1988, we have incorporated dementia prevention activities into our systematic health education programs, targeting young older adults in five areas of Nagano Prefecture. Through these programs, we have administered comprehensive social capital-oriented health education based on fostering empathy and cooperation. In 2014, these health education systems were awarded International Organization for Standardization (ISO) 9001; QC14J0022 certification, which is an international standard [5-8].

In Thailand, in 2005, the percentage of the population over 65 years of age was 7\%, and this percentage is expected to rise to $14 \%$ by 2025 ; meanwhile, in Indonesia, this percentage is projected to reach $7 \%$ by 2020 and $14 \%$ by 2045 . Thus, in addition to Japan, several other Asian countries are also facing challenges regarding their aging populations [9]. Consequently, implementing an ISO-certified health education system such as the one that we have developed to promote dementia prevention activities can play an important role in this region, contributing to extending the population's life expectancy and controlling medical expenses [10-13]. Since 2013, in cooperation with Mahidol University, Thailand, and Udayana University, Indonesia, we have introduced our ISO-certified health education system into the areas surrounding both universities [14-17].

The purpose of this study was to collect data on the effects of an ISO-certified health education system and to study the feasibility of this program in new social contexts.

\section{Methods}

\subsection{General methods}

For this research, the ISO 9001; QC14J0022-certified health education system was introduced into the Nikhom Phatthana District, Rayong Province, central Thailand, and Denpasar City and Tabanan Regency, Bali, Indonesia (Fig. 1). The ISO is a non-governmental organization headquartered in Geneva, Switzerland, and its main activity is to establish internationally accepted standards [18]. Our ISO-certified health education system collects anthropometry, blood pressure, blood chemistry, physical fitness, and brain function data before and after the health education program. These data are collected in the same way in all countries (Fig. 2).

All participants were healthy, middle-aged to older adults (42-86 years) with no history of cardiovascular or pulmonary diseases. They provided written informed consent and were enrolled in the health education programs in their communities in Thailand, Indonesia, and Japan. Participants were informed of the safety of participation in this study. Participation in this study is voluntary and should not be adversely 


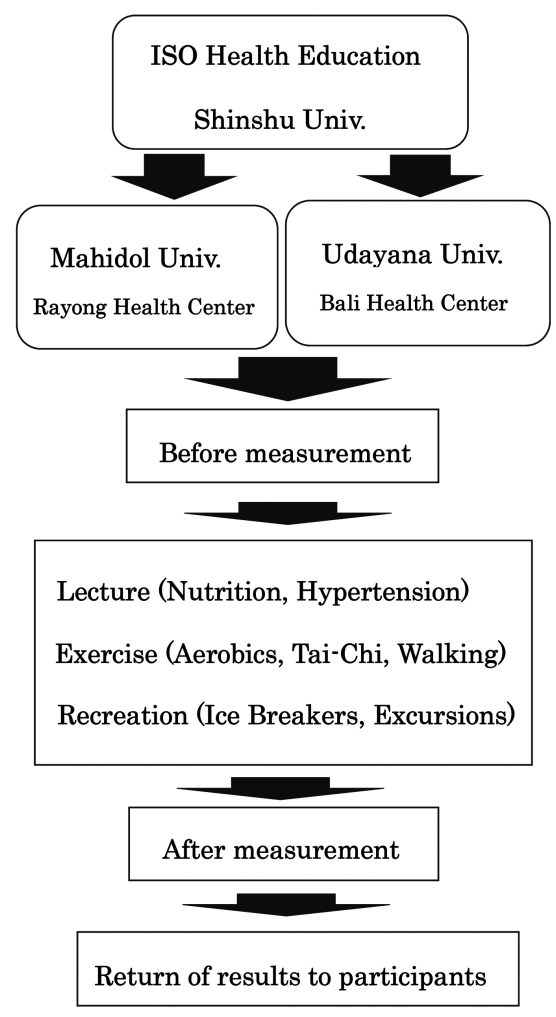

Fig. 1. ISO health education flowchart.

affected by non-participation. Even if they agree to participate once, they can withdraw at any time. The programs were offered by the health centers in each country. The participants agreed to participate in this research as volunteers after receiving a detailed explanation of the ISO-certified health program.

In Thailand, we implemented a six-month health education program from August 2013 to January 2014; in Indonesia, we implemented a seven-month program from February to August 2014; and in Japan, we implemented a six-month program from June to November 2013. Before and after the implementation of the health education program, we conducted physical fitness, blood chemistry, and brain function tests. The control participants were not given pedometers. There were 114 Thai participants (aged $60.5 \pm$ 11.1 years; 31 men [66.3 \pm 7.1 years] and 83 women [ $58.3 \pm 11.5$ years]), 119 Indonesian participants $(66.0 \pm 6.2$ years; 41 men $[67.7 \pm 5.7$ years] and 78 women $[65.1 \pm 9.6$ years]), 43 Japanese participants (63.2 \pm 4.4 years; 17 men [61.8 \pm 4.1 years] and 26 women [65.5 \pm 4.0 years]), and seven Japanese participants who served as controls (61.3 \pm 7.8 years: three men $[66.0 \pm 2.5$ years] and four women [57.8 \pm 9.5 years]). At the beginning of the study, all participants in Thailand, Indonesia and Japan were given a lecture regarding the importance of maintaining health, especially the effect of walking 7,000 steps a day, which leads to improvements in anthropometry, blood pressure, physical fitness, blood chemistry, and brain function. All participants in Thailand, Indonesia and Japan attended a series of classes regarding recreational activities such as aerobics, stretching or yoga (see Table 1); these classes lasted 90 min each and were conducted twice a month. All exercise were measured by the pedometer.

This research was approved by the institutional ethics committees of Mahidol University (no. 01-58-10) and Shinshu University (no. UMIN000009309) and in accordance with the code of ethics of the World Medical Association. Written informed consent was obtained from all participants. 
Table 1

Program contents of the health education in Thailand, Indonesia, and Japan

\begin{tabular}{|c|c|c|c|}
\hline Month & Thailand & Indonesia & Japan \\
\hline Feb. & & $\begin{array}{l}\text { 1. Measurements before the health } \\
\text { education }\end{array}$ & \\
\hline Mar. & & 2. Specific exercise & \\
\hline Apr. & & 3. Fun walk around the village & $\begin{array}{l}\text { 1. Measurements before the health } \\
\text { education }\end{array}$ \\
\hline May & & $\begin{array}{l}\text { 4. Psychologic and brain function } \\
\text { exercise }\end{array}$ & $\begin{array}{l}\text { 2. Lecture on health education and } \\
\text { nutrition }\end{array}$ \\
\hline June & $\begin{array}{l}\text { 1. Measurements before the health } \\
\text { education }\end{array}$ & $\begin{array}{l}\text { 5. Traditional orchestra and religious } \\
\text { song }\end{array}$ & 3. Practice of yoga and recreation \\
\hline July & 2. Aerobic exercises & 6. Exercise and walk & $\begin{array}{l}\text { 4. Promoting the use of muscle } \\
\text { strength and walking }\end{array}$ \\
\hline Aug. & 3. Aaerobic exercises & $\begin{array}{l}\text { 7. Measurements after the health } \\
\text { education }\end{array}$ & $\begin{array}{l}\text { 5. Excursion in town and practical } \\
\text { skill of Tai Chi }\end{array}$ \\
\hline Sept. & 4. Lecture on blood pressure & & $\begin{array}{l}\text { 6. Measurements after completion of } \\
\text { the program }\end{array}$ \\
\hline Oct. & 5. Visit to the temple & & \\
\hline Nov. & $\begin{array}{l}\text { 6. Measurements after completion of } \\
\text { the program }\end{array}$ & & \\
\hline
\end{tabular}

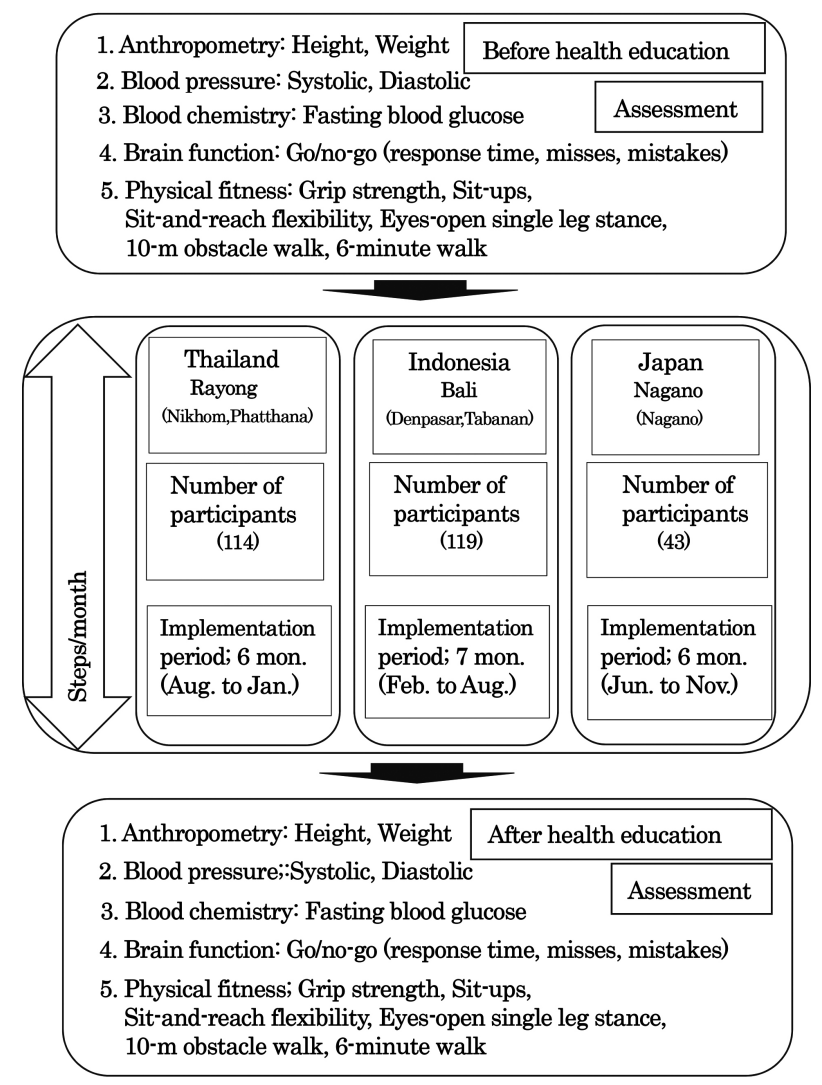

Fig. 2. ISO 9001 health education services implementation status. 


\subsection{Pedometry}

The number of steps taken each day and energy expenditure were measured using a pedometer (Acos Co. Ltd., Japan; JP800). Daily total steps were divided into "exercise-related" steps (steps exceeding four metabolic equivalents [METs]) and "normal" steps (less than four METs). For all groups, steps were measured throughout the program period.

\subsection{Anthropometry, blood chemistry measurements and blood pressure measurements}

These measurements and the blood chemistry measurements were taken when the participants were in a fasted state ( $>10 \mathrm{~h}$ since the previous meal). The company responsible for performing the blood tests (Hokushin Co.) reported the measured values of each parameter. Systolic and diastolic blood pressures were measured via auscultation (mercury sphygmomanometer, Kenzumedico 0601B001, Japan) after the participants had been sitting for $15 \mathrm{~min}$ in a room with an ambient temperature of $25^{\circ} \mathrm{C}$ and a relative humidity of approximately $50 \%$.

\subsection{Physical fitness tests}

The administered physical fitness test was approved by the Japanese Ministry of Education, Culture, Sports, Science and Technology [19]. This test (target age: 65-79 years) features six physical assessments: hand-grip strength, sit-ups, sit-and-reach flexibility, an eyes-open single-leg stance, a 10-m obstacle walk, and a six-minute walk test. The participants' physical ability was assessed before and after the health program.

\subsection{Brain function tests}

The go/no-go task [20-22] was used to estimate the inhibitory decision-making process, and this task consisted of three experimental stages: formation, differentiation, and reverse differentiation. First, in the formation stage, which consisted of five trials, the participants were instructed to squeeze a rubber ball in response to the illumination of a red light, which occurred at random intervals. Second, during the differentiation stage, the participants squeezed the rubber ball in response to the red light but refrained from doing so when the yellow light was illuminated. Third, during the reverse differentiation stage, the participants squeezed the rubber ball in response to the yellow light but not the red light. The differentiation and reverse differentiation stages consisted of 20 trials each; in both, the red and yellow lights were randomly illuminated 10 times each.

\subsection{Statistical analyses}

One-way analysis of variance (ANOVA) was performed to compare the step counts of the three groups, and when a significant difference was observed, Tukey-Kramer post hoc comparisons were performed. Two-way repeated-measures ANOVA was employed to compare the results before and after the health education program. When significant interactions were found, one-way ANOVA was conducted; then, Tukey-Kramer post hoc comparisons were performed if ANOVA showed significant results. Additionally, a paired-samples $t$-test was used to compare the health measurement results before and after the health education program for each group: Thailand, Indonesia, Japan, and the control group. The level of significance was set at $p<0.05$. Statistical analyses were performed using SPSS Statistics version 26 (IBM Corp., Armonk, NY, USA). 
Table 2

Pedometry comparison of the steps in Thailand, Indonesia, and Japan

\begin{tabular}{lccccccc}
\hline & Thailand & Indonesia & Japan & & One way ANOVA & \multicolumn{3}{c}{ Tukey-Kramer ( $p$ value) } \\
\cline { 6 - 8 } & & & & $p$ value & T vs. I & I vs. J & T vs. J \\
\hline Walking steps & & & & & & & \\
Total/day (steps) & $4,700 \pm 410$ & $4,410 \pm 60$ & $5,330 \pm 600$ & 0.006 & NS & 0.05 & NS \\
Exercise-related/day (steps) & $1,370 \pm 50$ & $1,740 \pm 40$ & $2,780 \pm 460$ & 0.001 & 0.01 & 0.01 & 0.01 \\
\hline
\end{tabular}

T: Thailand $(N=114)$, I: Indonesia $(N=119)$, J: Japan $(N=43)$.

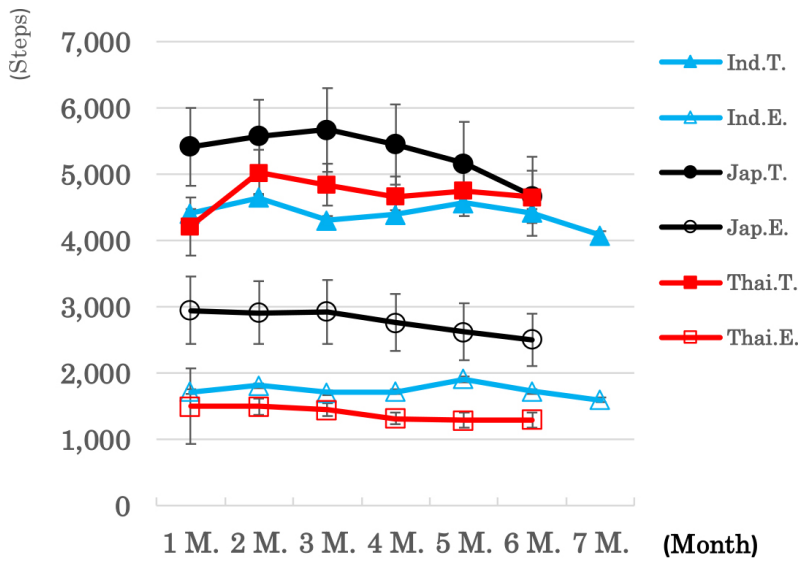

Fig. 3. The average daily number of total and exercise-related steps taken each month by the Thai, Indonesian, and Japanese participants. M; month, T; total steps, E; exercise-related steps.

\section{Results}

\subsection{Pedometry}

Figure 1 shows the average daily number of total (normal steps + exercise-related steps) and exerciserelated steps taken each month by the Thai, Indonesian, and Japanese participants. Among the Thai participants, for the six-month period overall, the average number of total steps was 4,700 \pm 410 , and the average number of exercise-related steps was 1,370 \pm 50 . In Indonesia, for the seven months overall, the average number of total steps was $4,410 \pm 60$, and the average number of exercise-related steps was $1,740 \pm 40$. In Japan, for the six-month period, the average number of total steps was 5,330 \pm 600 , and the average number of exercise-related steps was 2,780 \pm 460 (Fig. 3). There are no data for the Japanese control participants, as they were not given pedometers. The values were significantly larger for the Japanese group than for the Indonesian group, and they were larger for the Indonesian group than for the Thai group (Table 2).

\subsection{Anthropometry, blood pressure measurements and blood chemistry measurements}

The Thai participants' weight significantly increased after the program. For the Indonesian participants, their systolic blood pressure was significantly different. The interaction of the minimum blood pressure in two-way ANOVA significantly differed; consequently, one-way ANOVA was used to interpret the before and after results of all groups; this analysis showed no significant difference (Table 3). 


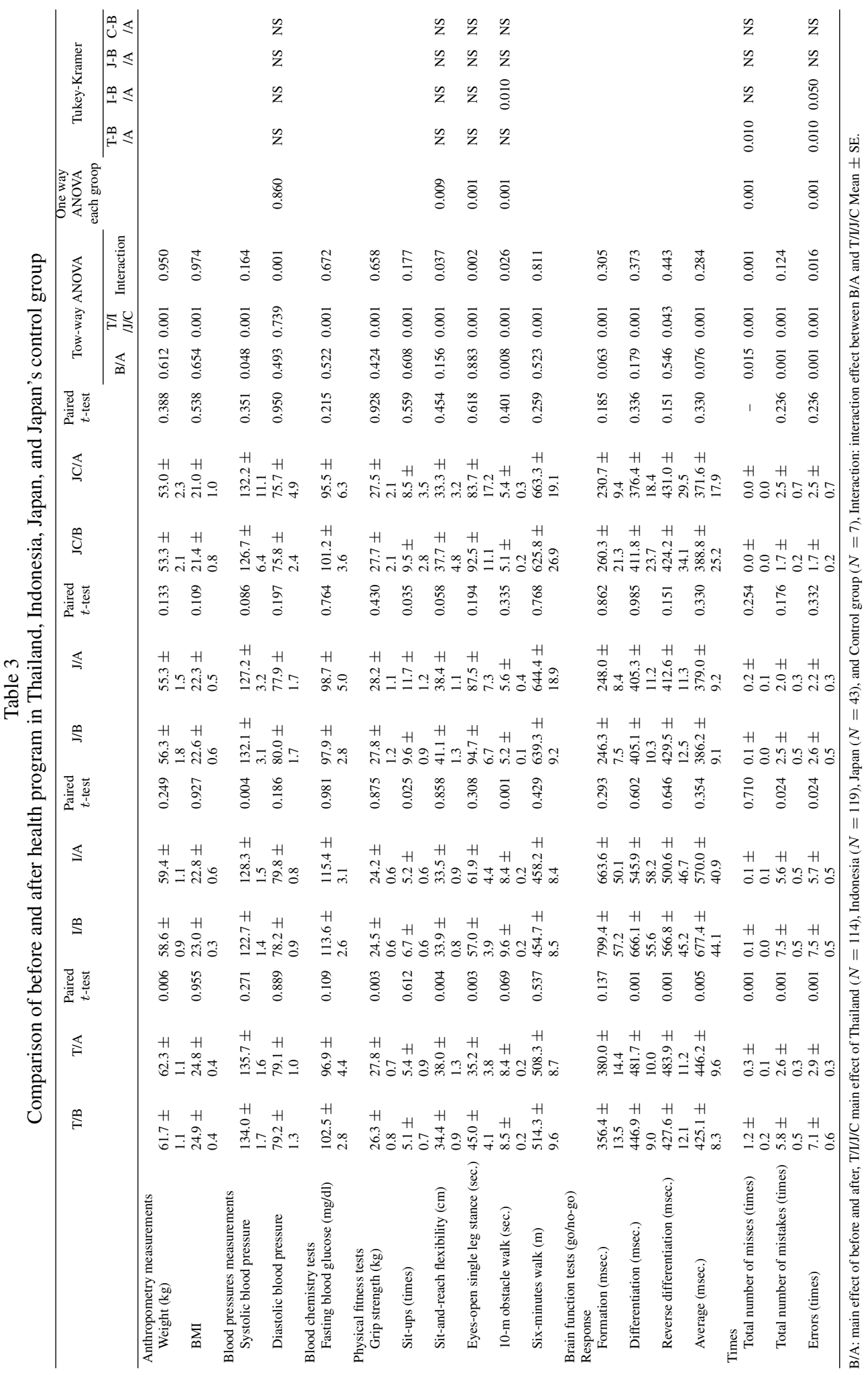




\subsection{Physical fitness measurements}

For the Thai participants, hand-grip strength and sit-and-reach flexibility significantly increased; in contrast, performance on the eyes-open single-leg stance significantly worsened. For the Indonesian participants, performance on the 10-m obstacle walk significantly improved; however, the number of sit-ups significantly decreased. For the Japanese participants, the number of sit-ups significantly increased. The interaction of sit-and-reach flexibility, the eyes-open single-leg stance, and the 10-m obstacle walk in two-way ANOVA was significant; thus, one-way ANOVA was used to interpret the before and after results of all groups. The results for sit-and-reach flexibility and the eyes-open single-leg stance showed no significant differences; however, among the Indonesian participants, performance on the 10-m obstacle walk significantly improved (Table 3 ).

\subsection{Brain function measurements}

For the Thai participants, the average differentiation reaction times, reverse differentiation reaction times, and total reaction times significantly increased after the program. Meanwhile, the total number of "misses", "mistakes", and errors significantly decreased after the program. The interaction of the total number of "misses" and errors was significant. The total number of "misses" among the Thai participants and the total number of errors among the Thai and Indonesian participants significant decreased.

\section{Discussion}

Regarding exercise-related steps, the Thai, Indonesia and Japan participants respectively, took 1,395 (30\% of the number of total steps), 1,744 (40\% of the number of total steps), and 2,782 (55\% of the number of total steps) daily steps. In the future, it will be necessary to make an effort to increase the number of exercise-related steps. It has been reported that such walking is effective at preventing dementia; forty minutes of active walking a week over the course of a year results in a $2 \%$ increase in the hippocampal volume and improves memory [23].

The Thai participants' weight increased significantly after the health education program. Conversely, the other participants lost weight, but the difference was not statistically significant. The participants' BMI values did not significantly change in any group. In previous studies, significant improvements in body weight, BMI, blood pressure, and blood chemistry were found when the subjects incorporated walking and exercising into their lifestyle [3,24-26]. Thus, increasing the average number of total steps may help the participants in the present study improve in this regard.

Among the Thai participants, hand-grip strength and sit-and-reach flexibility significantly increased; in contrast, performance on the eyes-open single-leg stance test significantly worsened. For the Indonesian participants, performance on the 10-m obstacle walk significantly improved, while the number of sit-ups significantly decreased. For the Japanese participants, the number of sit-ups significantly increased. However, there are few improvement items for physical fitness in Thailand, Indonesia, and Japan. If the average number of total steps taken by participants is 7,000 or more, the improvement rate of physical fitness measurement items will significantly increase [5-8].

Go/no-go tasks are frequently used to investigate response inhibition, which is an essential executive function performed by the prefrontal cortex, as well as a variety of other cognitive components [20-22, $27,28]$. In the present study, the interaction between the total number of "misses" and "mistakes" was significant for all groups. The Thai and Indonesian groups had significantly fewer total "misses" and 
errors after the program. Previous go/no-go task studies suggest that a health program could improve brain function [5-8]. In the first stage of the go/no-go task, the reaction time is short and the number of errors is large. Participants performed regular exercises in the second stage, and the go/no-go task reaction times increase and the number of error responses decreased. In the third stage, the go/no-go task reaction times decreased significantly, and the number of error responses decreased significantly. In the Thai participants, the go/no-go results for the first stage improved.

Since pedometers were not given to the control group in Japan, there are no data on the number of steps taken by this group. However, in another study [29], control group members were 5,220. In this survey, the target value of 7,000, and also the target value of 7,000 steps by 2022 established by the Ministry of Health, Labor and Welfare of Japan by people aged 65 and over [30]. The target value of 7,000 steps was not achieved in all areas; only a few measurement items of anthropometry, blood pressure, blood chemistry, physical fitness, and brain function showed improvement, and some even showed a significant decrease as the participants aged. Therefore, it is important for participants to encourage and sympathize with each other and continue their health education program with the aim of achieving more than 7,000 steps without dropping out.

\subsection{Limitations}

In this study, our ISO 9001 program was provided for six months in both Japan and Thailand; however, in Indonesia, it was provided for seven months. The reason is that in Indonesia, the schedule for the ISO staff was not set; thus, the assessment was postponed by one month. Japanese participants were from Nagano City, Nagano Prefecture, Japan, and a control group composed of senior citizens, also in Nagano, was created. There were only seven participants in the control group since 17 participants dropped out; therefore, a control group was created only for the Japanese participants.

\section{Conclusions}

The purpose of this study was to collect data on the effects of an ISO-certified health education system and to study the feasibility of this program in new social contexts. To that end, we implemented the health program in Thailand and Japan, recruiting 114 and 43 participants, respectively, and in Indonesia, recruiting 119 participants. The participants' conditions before and after the program were determined through anthropometry, physical fitness, blood chemistry, and brain function tests and pedometry. The Japanese participants in our study took 5,330 daily steps, the Thai participants took 4,696 daily steps, and the Indonesian participants took 4,406 daily steps. The target value of 7,000 steps was not achieved in all areas; only a few measurement items of anthropometry, blood pressure, blood chemistry, physical fitness, and brain function showed improvement, and some even showed a significant decrease as the participants aged. Therefore, it is important for participants to encourage and sympathize with each other and continue their health education program with the aim of achieving more than 7,000 steps without dropping out.

\section{Acknowledgments}

The authors would like to thank all individuals who participated in this study. 


\section{Author contributions}

KT, AG, AN, SM, SK, TW, NT, RU and KA planned the experiment and collected the data. FS, MO, KK, HK and HT performed the data analysis. MK, TF, TN, KT and HT composed the article. All authors read and approved the final manuscript.

\section{Availability of data and material}

The data and materials are available.

\section{Conflict of interest}

The authors have no conflicts of interest to report.

\section{Funding}

Koji Terasawa is supported by grants-in-aid for scientific research (Kiban A: 16H02713) from the Ministry of Education, Culture, Sports, Science and Technology of Japan. The funder had no involvement in study design, the collection, analysis and interpretation of data, the writing of the report, or the decision to submit the article for publication.

\section{References}

[1] World Health Organization. Primary health care: Report of the international conference on primary health care. Almata-Ata, USSR, 6-12. World Health Organization, Geneva. 1978

[2] Kickbusch I. Health promotion, a global perspective. Can. J. Public. Health. 1986; 77: 321-327.

[3] de Vries NM, van Ravensberg CD, Hobbelen JS, Olde Rikkert MG, Staal JB, Nijhuis-van der Sanden MW. Effects of physical exercise therapy on mobility, physical functioning, physical activity and quality of life in community-dwelling older adults with impaired mobility, physical disability and/or multi-morbidity: A meta-analysis. Ageing Res Rev. 2012; 11(1): 136-149.

[4] Ministry of Health, Labor and Welfare. Standards of Physical Activity for the Creation of Health. 2013. http://www.mhlw. go.jp/stf/houdou/2r9852000002xple-att/2r9852000002xpqt.pdf (accessed 14 September 2020) [in Japanese].

[5] Watanabe T, Terasawa K, Nakade K, Murata Y, Terasawa S, Kobayashi I, Kobayashi T, Nakajima K, Zhang Y, Maruo JS, Sasamori F, Hirota N, Okuhara M. Influence of two different health promotion programs on walking steps, anthropometry, blood pressure, physical fitness, blood chemistry and brain function. I. J. Med. Heal. Sci. 2015; 5: 170-181.

[6] Murata Y, Nemoto K, Kobayashi I, Miyata Y, Terasawa S, Sasamori F, Nakajima K, Hirota N, Kobayashi T, Zhang Y, Watanabe T, Okuhara M, Nakade K, Maruo JS, Terasawa K. Effect of a two-year health program on brain function, physical fitness and blood chemistry. J. Community. Med. Health. Educ. 2015; 5: 1-6.

[7] Nakade K, Fujimori S, Watanabe T, Murata Y, Terasawa S, Maruo JS, Adiatmika IPG, Adiputra IN, Muliarta IM, Terasawa K. A case study of health education from Nagano prefecture in Japan: The relationship between health education and medical expenses. J. Community. Med. Health. Educ. 2017; 7(3): 1-6.

[8] Fujimori1 S, Maruo JS, Watanabe T, Taki N, Sasamori F, Kobayashi K, Akasaki H, Okuhara M, Uchiyama R, Ashida K, Tabuchi H, Terasawa K. Effectiveness of a Japanese-style health program in Minowa town, Matsumoto city and Nagano city Japan. International Journal of Human Rights in Healthcare. 2020; 1-17. doi: 10.1108/IJHRH-01-2020-0002.

[9] United Nations. World population prospects: The 2010 revision. 2011. http://www.un.org/en/development/desa/population/ publications/pdf/trends/WPP2010/WPP2010_Volume-I_Comprehensive-Tables.pdf (accessed 30 Septmber 2020).

[10] World Health Organization, 2016. World health statistics 2016. http://www.who.int/gho/publications/world_health_statisti cs/2016/en/ (accessed 14 September 2020). WHO Press, World Health Organization, Geneva, Switzerland. 
[11] Bram W, Martijn H, Bert RM, Dorly JHD, Johan J. The effect of trends in health and longevity on health services use by older adults. BMC Health Serv. 2015; 15: 574. doi: 10.1186/s12913-015-1239-8.

[12] Zhuo X, Zhang P, Gregg EW, Barker L, Hoerger TJ, Tony P-C. A nationwide community-based lifestyle program could delay or prevent type 2 diabetes cases and save $\$ 5.7$ billion in 25 years. Albright A. Health Aff. 2012; 31(1): 50-60. doi: 10.1377/hlthaff.2011.1115.

[13] Ministry of Health, Labor and Welfare. "Research group on the effect of extending healthy life expectancy" Discussion summary- “, 2020. https://www.mhlw.go.jp/content/10904750/000495774.pdf (accessed 14 September 2020).

[14] Maruo JS, Sanongdetch W, Choeychom S, Chansirikarn S, Thrakul S, Phuphaibul R, Terasawa S, Nakade K, Watanabe T, Murata Y. Comparing the effectiveness of health program in Thailand and Japan. J. Nurs. Care. 2015; 4(5): 1-6.

[15] Terasawa K, Adiatmika PG, Adiputra N, Muliarta IM. Effects of health education in Asia comparing Thailand, Indonesia and Japan. The 6th Congress of the International Society for Physical Activity and Health, Bangkok, Thailand. 2016; pp. 16-19.

[16] Adiatmika IPG, Terasawa K, Adiputra N, Muliarta IM, Suchinda MJ, Nakade K, Watanabe T, Terasawa S, Kobayashi T, Zhang Y, Nakajima K, Sasamori F. Health education effects on physical fitness and blood chemistry among senior citizen in both rural and urban areas of Bali, Indonesia. The 6th Congress of the International Society for Physical Activity and Health, Bangkok, Thailand. 2016; pp. 16-19.

[17] Maruo JS, Noppawan P, Surintom K, Pinyo U, Siripon S, Tabuchi H, Akasaki H, Watanabe T, Taki T, Uchiyama U, Ashida K, Okuhara M, Terasawa K. The effectiveness of a health promotion program using the International Organization for Standardization in Klongyongand Nikhompattana, Thailand. Asian Journal Pharmaceutical and Clinical Research. 2020; 13(3): 1-6.

[18] International organization for standardization. 2018. https://www.iso.org/about-us.html (accessed 14 September 2019).

[19] Ministry of Education, Culture, Sports, Science and Technology, 2001. Shintairyoku testo jisshi youkou (Implementation Guideline for the New Physical Fitness Test) www.mext.go.jp/sports/b_menu/sports/mcatetop03/list/detail/1408001.htm (accessed 14 September 2020) [in Japanese].

[20] Masaki T, Moriyama G. Study on types of human higher nervous activity. J. Tokyo. Sci. Univ. 1971; 4: 69-81.

[21] Terasawa K, Tabuchi H, Yanagisawa H, Yanagisawa A, Shinohara K, Terasawa S, Saijo O, Masaki T. Comparative survey of go/no-go results to identify the inhibitory control ability change of Japanese children. Biopsychosoc. Med. 2014a; 14: $1-8$.

[22] Terasawa K, Misaki S, Murata Y, Watanabe T, Terasawa S, Kobayashi T, Yong Z, Nakajima K, Maruo JS, Nakade K. Relevance between Alzheimer's disease patients and normal subjects using go/no-go tasks and Alzheimer assessment scores. J. Child. Adolesc. Behav. 2014b; 2(4): 1-5.

[23] Erickson KI, Voss MW, Prakash RS, Basak C, Szabo A, Chaddock L, Kim JS, Heo S, Alves H, White SM, Wojcicki TR, Mailey E, Vieira VJ, Martin SA, Pence BD, Woods JA, McAuley E, Kramer AF. Exercise training increases size of hippocampus and improves memory. Proc. Natl. Acad. Sci. U. S. A. 2011; 108(7): 3017-22.

[24] Hamer M, Chida Y. Walking and primary prevention: A meta-analysis of prospective cohort studies. Br J Sports Med. 2008; 42: 238-43.

[25] Hornbuckle LM, Kingsley JD, Kushnick MR, Moffatt RJ, Haymes EM, Miles R, Toole T, Panton LB. Effects of a 12-month pedometer-based walking intervention in women of low socioeconomic status. Clin Med Insights Womens Health. 2016; 6(9): 75-84.

[26] Zahra G, Ali AH, Sakineh MA, Jamileh A, Farzaneh Z. A comparison of HbA1c and fasting blood sugar tests in general population. Int J Prev Med. 2010; 1(3): 187-94.

[27] Diamond A. Executive functions. Annu. Rev. Psychol. 2013; 64: 135-168.

[28] Chikazoe J. Localizing performance of go/no-go tasks to prefrontal cortical subregions. Curr. Opin. Psychiatry. 2010; 23: 267-272.

[29] Terasawa K, Kumagaya A, Ishikura S, Murata Y, Watanabe T, Taki N, Uchiyama R, Ashida K. A consideration for improving daily walking activity-from the step survey of infants to high school students and the elderly. Nagano Journal of Physical Education and Sports, 54th Annual Conference. 2019; p. 16.

[30] National Institute of Health and Nutrition, The second term of National Health Promotion Movement in the twenty first century. [homepage on the Internet]. Tokyo: Ministry; 2017. http://www.nibiohn.go.jp/eiken/kenkounippon21/kenkounippon 21/data05.html (accessed 30 August 2020) [in Japanese]. 